\title{
MULTIPLE FOREST USE AND ITS APPLICATION ON THE ROCKY MOUNTAIN FOREST RESERVE ${ }^{2}$
}

\author{
By E. S. FELLOW $\mathbf{S}^{2}$
}

Probably there is no other forested area of comparable size in Canada that is so fully dedicated to the principle of multiple use as is the Rocky Mountains Forest Reserve. That is not a new situation; it was the case even before the term "multiple-use" found its way into the forester's jargon. It is fitting then that this subject should be chosen for a convention held here on the spinal column of the continent where sheep and snow, beef and bears, coal and camping, trout and trail-riding, elk and electric power, pine and petroleum, all make their contributions to the economy and the charm of this Canada of ours. It is fitting too, perhaps, that this subject should have been given the honour of following the theme paper of the convention.

If there has been any recent change in the policy of management on Forest Reserve on the eastern slope of the Rockies, it has been one of emphasis rather than of basic concept - an emphasis made necessary by the ever increasing pressure of civilized man on nature. Less than a half-century ago this was a pioneer land in a very real sense, a seemingly endless expanse which could never be anything but the "wild west". But in that half-century -that short life-time--the population of this country has almost tripled; it has grown to be one of the great industrial and exporting nations in a world which itself has increased its population by almost fifty per cent in the same period. Surely it is not necessary to say more about the pressure of man on nature! The increasing demand for beef, for wheat, for timber, for wool, for coal, for oil and above all for good water-water for crops, water for industry, water for people-is all the evidence needed.

We have all heard of the devastation of great areas in China and the Near East caused by unwise land-use. We have noted the symptoms of similar devastation making their appearance in many parts of North America, and we are alarmed. The truth that it can happen here begins to be accepted. It was that realization, coupled with the determination that it must not happen here, which no doubt prompted the establishment of the Eastern Rockies Forest Conservation Board.

Since this is a paper on multiple forest use, it cannot go into a full description of administrative machinery. However, for a better understanding of the problems and how they are being met, a few words on the Eastern Rocky Mountains Forest Conservation Act seem necessary. This federal act, with its provincial counterpart, set up a three-man board whose duty it is to develop a plan of management for the greater part of the forested area forming the headwaters of the Saskatchewan river, with the exception of the National Parks. It is a policy-making body only, but within that field has wide powers over most matters affecting the vegetal cover and the soil mantle. The title to the area remains exclusively with the Province of Alberta, and the administra-

\footnotetext{
I Presented at the annual meeting of the Canadian Institute of Forestry, Banff, Alberta, October 11-18, 1951 .

2 Chief Forester, Eastern Rockies Forest Conservation Board.
} 
tion of the Forest Reserves, within the policies laid down by the board, continues to be a function of the Alberta Forest Service, as has been the case for the past twenty years or so. The work of the board and the cost of administration of the area under its jurisdiction is financed jointly by the Governments of Canada and Alberta, except that all capital improvements are paid for by the federal government alone. These improvements must be completed during the first six years of the 25-year agreement. The funds available for both capital and maintenance accounts are fixed by statute.

The function of the board is to manage and protect the Forest Reserve with a view to obtaining the optimum flow of water in the Saskatchewan river and its tributaries. The increasing need for water has already been explained, but along with the growing demand there is apprehension over the possibility of a diminishing supply. The great glaciers of the Rockies, which contribute substantially to the summer flow of many of the larger streams, have been shrinking steadily for a number of years. In effect, this means that these streams are drawing on capital reserves of moisture rather than on the current snowfall and rainfall alone. Eventually this source of water may become almost negligible, and a compensating supply must be found elsewhere.

This situation gives the key to forest management policies. Water yield is the prime concern. Furthermore, the season at which the water is available may be just as important as the total annual flow. Water is most needed here in mid-summer. Therefore, anything which may tend to increase the amount of snow and spring rain reaching the ground or to decrease the use of water by mountain vegetation is important. But this alone might be dangerous and contribute to flood conditions. Management policies should aim at delaying the speed of snow melt and improving, or at least not impairing, the infiltration capacity of the soil. In short, everything possible must be done to get as much moisture as possible deep down in the soil, the subsoil, and even the underlying formations. From there it will move slowly and steadily into the streams or aquifers. These objectives must be kept in mind in regulating the various uses to which the Forest Reserve is put.

To the stranger, the eastern face of the Rockies may look like a grand but forbidding and inaccessible wilderness, but that is not so much the case as it appears to be on the surface. It is, in fact, subject to very considerable use and exploitation, The two principal uses which directly affect the vegetal cover are logging and grazing, while those which may also disturb the soilmantle locally are coal-mining, oil-prospecting, and road construction which is a prior need for most of the uses. The region is also famous as a sportsman's and recreationist's paradise. This latter use has only one important bearing on the board's work, namely, protection against fire. Game management is not a function of the board, but, as will be shown later, the board has a very considerable indirect interest in this activity.

It will be seen, then, the board has been set one main objective dealing with one function of the forest, namely, its capacity to control run-off. But it must also give the utmost consideration to those other forest uses which 
are of great importance to the economic welfare of the province and of the country at large. As is usual in the case of multiple-use of forest land, one use is dominant, although, by definition, not to the exclusion of others. It is the chief purpose of this paper to show how all uses are given their just consideration short of prejudicing the primary objective, and how these uses are controlled.

Before dealing with each of these uses separately, however, it might clarify the picture if the yardstick by which the possible prejudicing of the main objective by them is measured, In almost every case, this yardstick is to be found in the process of erosion. At first, it may sound rather absurd to be concerned about erosion in territory such as this. What harm can come of a few million tons of rock and soil moving away from these mountains? Is not erosion nature's way of wearing down mountains and of building plains? Geologic erosion is a perfectly natural and unavoidable process; it is taken for granted. But, accelerated erosion-sheet erosion or gullying-is not. The unduly rapid loss of soil from the area and the silting of streams could become quite a serious matter, but it is not the obvious results of accelerated erosion which are the chief cause of concern but the less apparent conditions of which erosion is the most easily recognized symptom.

In the mountains, accelerated erosion by wind is not a significant factor; water erosion is the principal danger. Now, to suffer water erosion it is necessary to have water travelling over the surface of the ground at such speeds, and in such volume, that it is capable of carrying appreciable quantities of soil with it. This is clearly not a general practice of nature, for, if it were, we should have no soil. It would be washed into the rivers and oceans as fast as it could be formed. In all but exceptional circumstances, the soil beneath an undisturbed and natural vegetal cover will absorb or contain the amounts of rain or melting snow to which it is normally exposed.

But man, by disturbing the vegetal cover through logging, grazing, cultivation, road building or other means, materially affects the capacity of the soil to permit the passage of water through it, and upsets those other factors which assist in this process. Thus, one of the sure signs that man has acted unwisely in such cases is the start of accelerated erosion. When this happens we know that water is flowing over the surface of the ground, instead of soaking steadily into it to emerge again as springs or seeps. Streams become turbid and rise and fall rapidly after short rains; the natural regulation has been upset. It is for this reason that those whose interests lie in the conservation of water develop a keen eye for erosion. They are not primarily concerned with the loss of soil or even with the silting of streams or reservoirs, important though these are, but with the fact that water is moving out of control. They have then ceased to "conserve" water; it is being wasted inasmuch as it cannot be used most effectively.

Before a gathering of foresters, it is not necessary to dwell upon the significance of fire in the water economy of a region. However, to make the record more or less complete it should be put in first place and its chief effects briefly reviewed. The first and most serious result is usually that the duff and 
litter on the forest floor is destroyed and the mineral soil is exposed to the elements. The beating of the rain upon the bare ground compacts the surface hindering the penetration of water. Overland flow may begin slowly and the fine silt picked up may be re-deposited thus further sealing the surface layer. The stage is then set for an ever increasing surface-flow. The loss of the forest and its undergrowth also leads to an increase in surface evaporation. In spring, because of the loss of shade, the snow melts abnormally fast. At the same time, the lack of protective cover permits the frost to penetrate deep into the soil and this reduces percolation. Such a combination of circumstances generally results in a flash run-off, and it may be devastating on an area already rendered susceptible to erosion. In view of this, it is not surprising that a water conservation authority should be just as much concerned about fire as are the forest industries themselves.

The board's policy in relation to protection against fire does not differ materially from that of any other forest authority, except that perhaps young stands are considered to be of even greater importance than mature timber in the overall plan. The board has placed a great deal of emphasis on the construction of roads and trails to make all parts of the area more readily accessible. Improved radio communication is being installed and the detection system is being expanded. Of course, mechanized transport and fire fighting equipment have been greatly augmented.

Disease or insect attack can produce a situation very much akin to fire, and often they are even more difficult to control. In this connection, the board is very fortunate in having at its disposal the personnel and facilities of the Division of Forest Biology of the federal Department of Agriculture. So far as is known, there is, at the present time, no imminent danger of either widespread disease or insect infestation within the Forest Reserve, but it is reassuring to know that the area is constantly being patrolled by experts looking for incipient trouble spots.

Of the various uses to which the Forest Reserve is put, grazing is by far the most extensive in that each year cattle, sheep, and horses roam over hundreds of thousands of acres of mountain slopes in search of feed. A much more detailed analysis of the place of grazing in the multiple-use of western forests is to be presented later at this meeting. In this paper, therefore, the subject will be treated just fully enough to place this use in its proper perspective.

The economic importance of the livestock industry to the region is in itself sufficient to justify the use of the forest for grazing. But, added to this, grazing conducted under careful management is very effective in reducing the danger of forest fires. A good proportion of the forests of the east slope of the Rockies consists of grassy, open valleys, mountain meadows and parklike stands of timber. If the grass on these areas were unused, the accumulation of litter would represent a serious menace, possibly the most serious fire hazard of all.

There is little evidence to suggest that controlled grazing has any detri- 
mental effect on the renewal of forest cover, but if allowed to get out of hand, it can be harmful not only to tree growth and reproduction but also to water yield. Over-use not only increases the possibility of direct damage to young trees, but creates conditions favourable to surface run-off. If grass is eaten down too much, the soil is exposed to the mercy of the wind and rain, and sheet erosion is likely to follow. This form of over-use tends to be progressive, and gradually the most palatable and nutritious plants are killed out and the less desirable ones take over the site along with unpalatable weeds.

The unnecessary congregation of cattle in small areas near water, salt, or shade, and the trailing of animals down slopes can also be the direct cause of erosion, because this results in the compaction of the soil which in turn leads to a severe reduction in its infiltration capacity.

In the management of grazing on forest lands, therefore, several points are of special importance, First, cattle should not be allowed on the area in the spring until the growth of grass is well advanced and there is no danger of the animals catching up with grass growth, Second, the concentration of animals in any area should be kept down to that number which the land can support without any deterioration of plant composition and without reducing the ground cover below the danger point. Third, the animals must be kept uniformly distributed over the grazing area and not allowed to congregate in certain favourite spots. And fourth, the springs and seeps should be protected from trampling. If this latter is not done the water sources may cease to flow or, what is just as bad, the moisture may be evaporated from muddy bogs, and contribute little or nothing to the flow of the streams.

Where herbivorous game animals are plentiful, it is clear that no plan for the management of domestic livestock can be wholly effective unless the needs and habits of the native fauna are taken into account. This fact accounts for the board's interest in game management which was referred to earlier in this paper. All grazing management plans prepared by the board give due weight to the forage needs of a normal population of wild animals. If game appears to be abnormally abundant, provincial game officials are consulted about ways of restoring a proper balance.

Logging is quite an important activity on the Forest Reserve, and in recent years five or six million cubic feet of timber of all kinds have been cut annually. To the water conservationist there are three principal aims in the management of logging. These are to see that adequate ground cover remains after the operation, and that regeneration is secured; to ensure the least possible fire hazard after the cut; and to see that the operation is conducted in such a way that the skid trails, roads and other facilities are so constructed that they will heal as quickly as possible. It is not the concern of the water conservationist to strive for the maximum yield of timber per acre, in fact this may even be detrimental to the water yield. Nor is his main concern the species or the quality of the ultimate products of the forests, though usually he is interested in the growing of those species most sought after by industry, provided that this does not conflict with his primary aim of getting clear water from the land. 
On the Forest Reserve the policy is to allow fully mature timber to be cut. A fairly high diameter-limit is set, however, to ensure adequate cover on the area after the operation. Brush disposal by lopping and scattering is favoured on the grounds that the brush gives some protection to the ground after logging and seems to permit of as good reproduction as any other method of slash disposal. Burning brush, on the other hand, is apt to do appreciable damage to the remaining timber without any significant offsetting advantages. Complete destruction of brush also robs the soil of the extra protection it should get in compensation for the disturbance of the stand.

In logging, as in other activities, it is necessary to beware of sowing seeds of erosion. Under some circumstances, the mere removal of a substantial part of the forest cover may be the start of such trouble. Always, however, the danger of erosion is present where roads and skid trails are built. As time goes on, more and more attention will be paid to the soil types in logging areas, but more information on erodibility of soils must be gathered before this can be done as a general practice. At present, the steepness of slopes is the principal guide in judging erodibility.

As to the most desirable kind of forest cover needed to promote the maximum water yield, much yet remains to be learned. It is very doubtful whether the sort of forest cover which would most please the logger is the optimum for producing water. It is nevertheless probable that there is a point of compromise at which forest lands will provide adequate yields of both water and timber. However, the water conservationist is not unhappy when he finds an open park-like stand of timber which provides the necessary shade and litter, and at the same time results in low water-losses from interception and transpiration.

In the control of mining, quarrying and exploration for oil, the policy has to be a rather negative one. That is to say, one of trying to prevent unnecessary damage to the vegetal cover and to the soil mantle and, where required, of ensuring as complete restoration as is practicable. It may be that, as time passes, it will be possible to turn some of these projects to the advantage of the water economy of the region. Abandoned strip mines may in time prove to be very good reservoirs for the storage of part of the spring run-off. The main concern at the moment, however, is to prevent such workings, and the roads leading to them, from becoming the cause of erosion and stream pollution. These dangers are particularly serious because few, if any, of the strip coal mines in the board's area are in valley bottoms. Most of them are well up on the mountain sides, and one or two are actually on mountain summits. For the time being, then, a balance must be struck between what appears to be ideally the best for the water economy and what is undeniably desirable for the economy of the region and the country as a whole -namely, the production of coal and oil. The best needs of the one cannot be permitted to entirely frustrate the other.

There is, at present, one hydro-electric development in the board's area. This is located in the valley of the Spray river, and delegates at this convention will have the opportunity of visiting this beauty spot. By nature, 
hydro-electric projects should fit well into a water conservation plan because, in performing their function, they tend to promote uniformity of stream-flow. In the construction of this spectacular development, therefore, the board's main concern was in seeing that the reservoir area and waterway were adequately cleared before flooding commenced, and that no unnecessary damage to the surface was done. This audience will be able to judge for itself how these requirements were met. Roughly four thousand acres of forest land were cleared for water storage and the resulting brush was burned with only one or two minor fires escaping from the project area.

It is very fortunate for this region that a great amount of research work on the influence of forest and other vegetation on stream-flow has been done in the United States and in many parts of Europe and Asia. Without the knowledge so gained the task of formulating management plans for the East Slope of the Rockies would be much more difficult than it is. However, even the best data obtainable from outside sources are of very limited value until there is a more thorough knowledge of local conditions. Because the region has been regarded as a wilderness area, relatively little information on climate, stream flow and soils has been gathered. Therefore, before the experience gained in other countries can be applied here, it is vital to know much more about these factors. To this end a number of weather stations are being established on the East Slope and a special effort is being made to obtain reliable data on precipitation.

The Water Resources Division of the Department of Resources and Development is co-operating with the Eastern Rockies Forest Conservation Board in establishing gauging stations on most of the principal streams rising in, or flowing through, the Forest Reserve. With a more accurate knowledge of how much precipitation falls on the area and how much water flows out in the streams, it will be possible to judge the effectiveness of the board's policies.

Along with these continuing studies, a number of special surveys are being conducted to determine the nature and extent of the natural resources. Besides the vegetal resources of grass and timber, the soils - and to a lesser extent the geology - are the subjects of special study, particularly the capacity of soil mantle and surface rock to absorb rainfall and snow-melt and to store moisture. The susceptibility to erosion of the various soil types is also receiving attention.

With a more complete knowledge of the extent and character of the precipitation over the area and of the nature of the soils on which this precipitation falls, it should be possible to arrive at sound management policies. For example, this information will be helpful in determining how certain areas should be grazed and whether timber should be cut in specific locations and, if so, how. It should be of the greatest value in determining what areas are of the highest watershed value and which are not worth any special consideration. It may also indicate the type of vegetal cover which is most desirable from the standpoint of water yield. In short, it will point to where an expenditure of effort will bring the greatest results, where the 
special danger areas are, and where conditions are such that no form of management can be expected to improve the water yield. All of this will lead to a better balanced multiple-use of the Forest Reserve as a whole. Until such time as more complete data on local conditions are available, however, the board's management policies must be based on an enlightened "play-safe" attitude founded on accepted broad principles. Briefly these are: an intensified system of prevention, detection and suppression of fire; a conservative grazing policy, with emphasis upon more methodical distribution of livestock on the range; timber management practices which will ensure the removal of mature timber by easy stages calculated to keep the water economy of the region in reasonable balance and provide for future forest cover; and the control of coal and oil developments with a view to obtaining proper drainage of roads, coal workings, etc.

It is sometimes argued that a watershed should, as far as possible, be maintained in its primeval condition, since in that state it probably provided a good, and well regulated, supply of clear water. But that reasoning is valid only if the whole balance of nature is regarded as an indivisible unit. Relating that argument to this particular region, for example, it is noted that the headwater area, as designed by nature, was associated with a vast buffalo range to the east. Man has chosen to convert that buffalo range into an immense area of cultivation. It is, therefore, no longer reasonable to assume that what nature provided to regulate the water system for a primeval community of plants, animals, and primitive man, will meet civilized man's new demands. The problem is to induce nature to release more water from the catchment area. But, to achieve this, nature must be coaxed and not bullied. If the latter approach is used, nature will surely revolt and the last state will be worse than the first.

Still another school of thought seems to believe that all one has to do to produce more water is to grow more trees. There is no scientific evidence whatever to support such a theory. Trees do not create water. The most they can do is to so alter a local environment (the micro-climate and soil charactertistics) as to facilitate the movement of water to the streams. Nearly everyone has observed the close association between water and trees, but what is really remarkable is that for some reason - perhaps wishful thinking - a majority seem to conclude that water is present because of the tree growth. To suggest the reverse is nearer the truth is regarded almost as heresy. It is largely in this affinity of trees for water that the subtle difference lies between water conservation and flood control. Trees are an even greater asset in preventing precipitation from reaching the rivers than they are in encouraging it to do so. They are, therefore, of more value in preventing floods than in augmenting the water yield.

If, in the foregoing discussion of forest influences, this paper seems to have digressed from the theme of multiple-use of forest lands, the digression may have been more apparent than real. The underlying argument is that, where high water-yield is the primary objective, it is probable that the concept of the multiple-use of forests has a better chance of adoption than under any other conditions. Where timber production is the paramount con- 
sideration, for example, grazing would necessarily be greatly restricted or completely eliminated. Where grazing land is the dominant need, the production of forest products would probably be encouraged only to the extent that the removal of the forest might add to the rangeland. In neither case would water production receive much consideration and, by the same token, fishing would suffer. Game animals would likely be unpopular with graziers and would receive scant sympathy from the logger. In short, to give over an area to the domination of either of these primary industries. would not favour the recreationist. But, at the same time, to dedicate an area exclusively to the recreationist is a disservice to the economy of the region and, at best, of very doubtful value in a programme of water conservation.

So long as Canadians believe that the greatest contribution the eastern slope of the Rockies can make to the national economy is in supplying an abundance of clear water, so long also are all other uses of the forest likely to receive fair, but not exclusive, consideration. This is so because most of these uses can be manipulated to help in achieving the main objective. The few others at least need not hinder its attainment. In the work and policies of the Eastern Rockies Forest Conservation Board, "multiple forest use" is not an end in itself nor yet the subject of empty platitudes. Though the board rarely uses the term, multiple-use is, in fact, the route which is followed every day, because it is the practical approach to the solution of the main problem, and also the one which contributes most to the overall welfare of the region. 